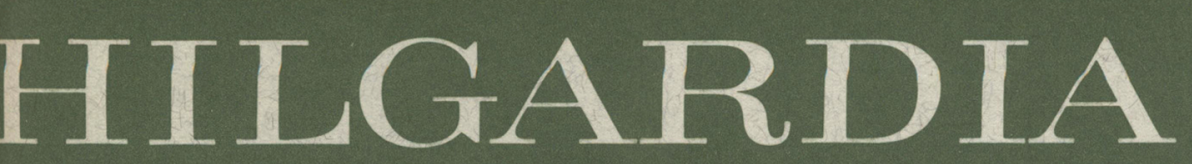

IJOURAL OF AGRICULTURAL SCIENCE PUBLISHED BY IHE CALIFORNIA AGRICULTURAL EXPERIMENT STATION

Volume 43, Number 5 - June, 1975

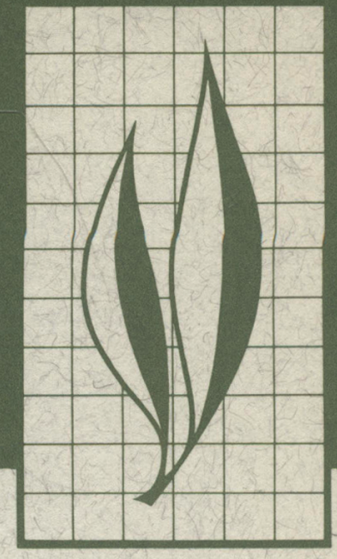

\title{
Computer Geheration of Points on a Plane
}

\section{Treatment of Boundary Line Overlap in a Forest-Sampling Simulator}

Lee C. Wensel 


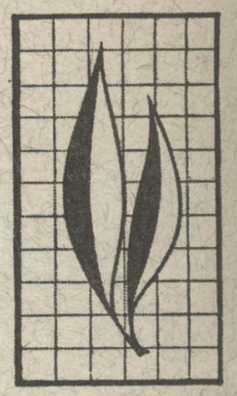

\section{COMPUTER GENERATION OF POINTS ON A PLANE}

A statistical model for the generation of random, contagious, and uniform spatial patterns is developed. Points are located on the plane one at a time with each point modifying the probability matrix for the next point. For random patterns no change is made in the probabilities. For contagious patterns, location of a point increases the probability of locating another point near it. However, for uniform patterns the probability of locating another point near previously established points is reduced.

\section{TREATMENT OF BOUNDARY LINE OVERLAP IN A FOREST-SAMPLING SIMULATOR}

A procedure is given for treating boundary line overlap in computer simulated sampling. This procedure, referred to as algorithm $E D G E$, insures that each point in the rectangular population has the same probability of being included in the sample, thereby eliminating possible edge-effect bias. The effectiveness of EDGE in producing a more realistic variance/plot size relationship is demonstrated by comparing the variance functions with uncorrected samples and samples corrected using a previously reported weighting scheme.

\section{THE AUTHOR:}

Lee C. Wensel is Associate Professor of Forestry, Department of Forestry and Conservation, College of Natural Resources, University of California, Berkeley, California 94720. 


\section{Treatment of Boundary Line Overlap in a Forest-Sampling Simulator ${ }^{2}$}

SIMULATION STUDIES USING either real populations that have been mapped or artificially-generated populations promise to be highly useful in studying the characteristics of biological communities. However, in dealing with these representations of real populations one must be careful in treating population elements located near the edge of the population. This is particularly important in computer-stored populations because they are usually quite small.
This paper proposes a procedure for projecting opposite sides of a population onto one another, thus making the computer-stored population effectively without boundaries. That is, population elements along opposite boundaries are treated as if they are physically adjacent to each other. An application of this concept in generating spatial patterns is made in subroutine LOCATE (see Appendix, starting page 147).

\section{COMPUTER SAMPLING OF MAPPED POPULATIONS}

In studying the efficiency of various forest-sampling designs it is common practice to map forest stands and store the Cartesian coordinates of each tree, together with the characteristics of that tree (diameter, height, volume, etc.), in a computer for study. This data set is then "processed" by a series of computer operations to simulate operations that would take place if the stand were sampled physically in the field. Using this technique, the efficiency of many different sampling designs may be tested easily once the initial mapping has been done. (O'Regan and Palley, 1965; Kulow, 1966; Wensel and John, 1969.)

Whether sampling in the field or with a computerized simulator, there exists the problem of getting a representative sample of trees near the forest's edge. If the probability of selecting a tree near the edge is different from the probability of selecting a similar tree in the interior, and if that probability difference is not considered in the estimate, the resulting estimator is biased. This is referred to as "slopover" bias (Grosenbaugh, 1958).

Let us consider fixed-radius plot sampling with a plot size of $a$ acres. Plot size $a$ is referred to as the nominal plot area, while the actual plot area may be somewhat less than $a$ because of the boundary overlap. In figure 1 , a tree is counted if the randomly located sample point falls within the plot area shaded for each tree. For tree 1, actual and nominal plot areas are equal; for tree 2 , the actual plot area is less than the nominal because of boundary overlap. Unbiased estimates of the total number of trees, total basal area, etc., will result if the actual probabilities of selecting the individual trees are used in developing the estimators.

Let us also consider the following esti-

\footnotetext{
${ }^{1}$ Submitted for publication October 26, 1973.
} 


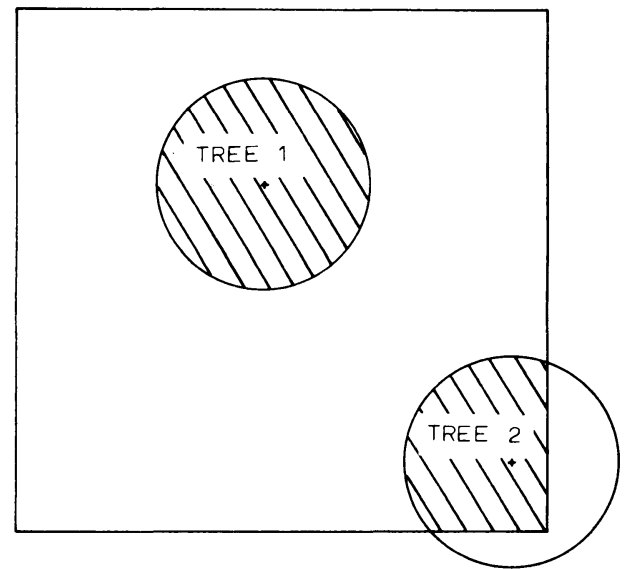

Fig. 1. Tree-plot boundary overlap.

mator $\hat{N}$ of $N$, the total number of trees in a forest of size $A$ :

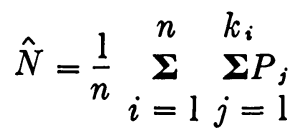

where $n$ is the number of randomly located sample points, $k_{i}$ is the number of trees counted at point $i$, and $P_{j}$ is the probability of selecting tree $j$ from a randomly located plot center. Note that

$$
P_{j}=\frac{a_{j}}{A}
$$

where $a_{j}$ is the plot area containing all sample points that would cause tree $j$ to be selected. If actual probabilities or plot areas are used, $\hat{N}$ is an unbiased estimator of $N$. Wensel and John (1969) give the necessary equations to compute the actual plot area using distances measured to the nearest boundaries. This approach, while time-consuming in the field and in the computer, gives exact results. However, for extremely small

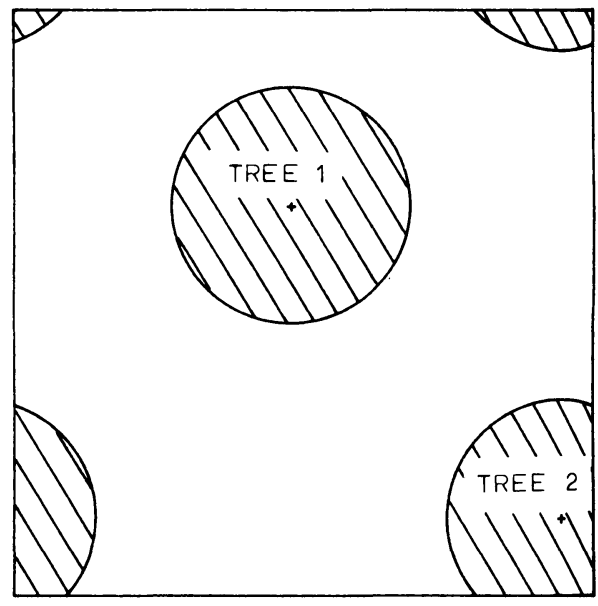

Fig. 2. Projection of overlap area to opposite boundaries.

populations where nominal and actual probabilities of selection can be quite different, the variance function (variance as a function of plot size) of the mapped stand may be somewhat different from the actual population being investigated.

In computer-stored populations it is possible to project opposite sides of the population onto one another so that, for example, the plot area that overlaps on the south boundary is transferred to the north boundary. Tree 2 in figure 2 would be counted if the randomly located sample points fall anywhere in the shaded areas. Thus the actual and nominal plot areas are always the same and $p$, the probability of selecting a given tree, is $a$ where $a$ is the nominal plot $\bar{A}$

area. The estimator $\hat{N}$ of $N$ then becomes

$$
\hat{N}=\left(\frac{1}{n}\right)\left(\frac{A}{a}\right) \underset{i=1}{n} k_{i}
$$

\section{ALGORITHM EDGE}

To compute the distance $r_{i}$ that a point $i$ with coordinates $\left(x_{i}^{2}, y_{i}^{\prime}\right)$ is from a plot center at point $\left(x_{0}, y_{0}\right)$ we proceed as follows:

$$
\begin{aligned}
& x_{i}=\min \left[\left|x_{i}^{\prime}-x_{o}\right|, x_{\max }-\left|x_{i}^{\prime}-x_{o}\right|\right] \\
& y_{i}=\min \left[\left|y_{i}^{\prime}-y_{o}\right|, y_{\max }-\left|y_{i}^{\prime}-y_{o}\right|\right]
\end{aligned}
$$

and 


$$
r_{i}=\sqrt{x_{i}{ }^{2}+y_{i}{ }^{2}}
$$

where $x_{\max }$ and $y_{\max }$ represent the maximum coordinates in the $x$ and $y$ directions, respectively. The individual $i$ would be included in the sample only if

$r_{i}$ is smaller than the plot radius $R$. A brief FORTRAN function to determine which individuals should be included in the plot when using this algorithm is given below.

FUNCTION EDGE ( $R, X, Y, X O, Y O, X M A X, Y M A X)$

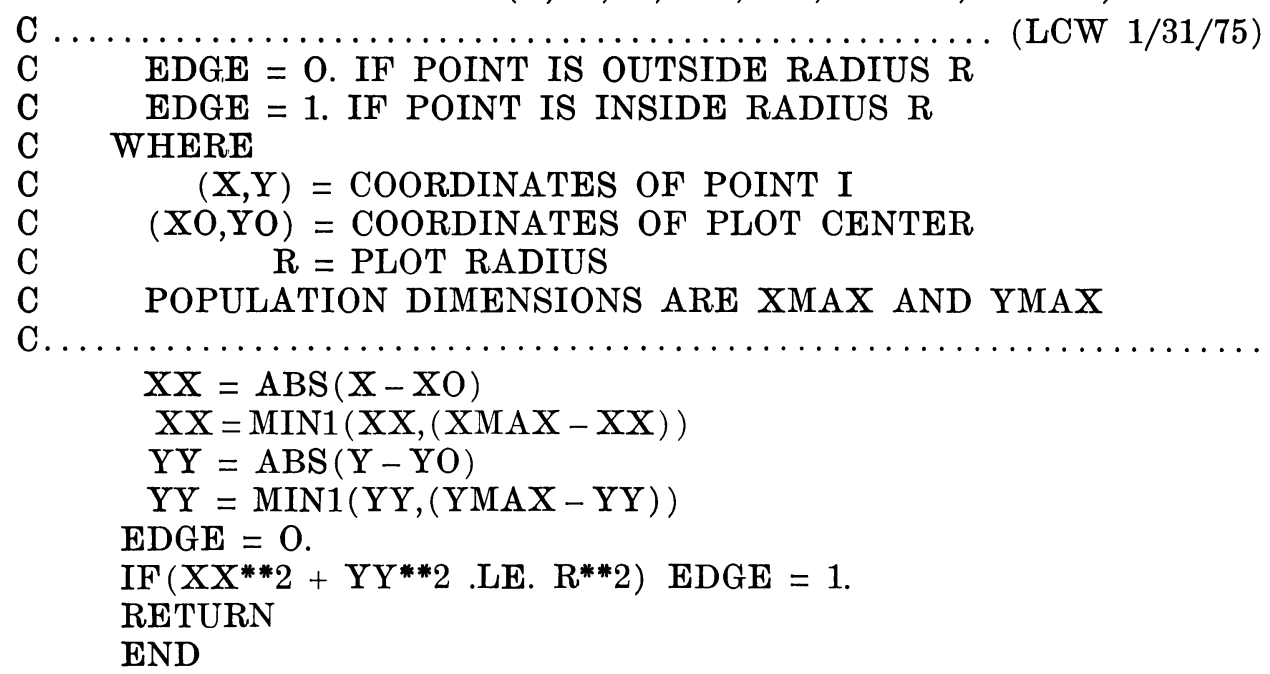

It is here assumed that any plot radius $R$ is less than one-half the smallest dimension of the area being sampled. Because the plot area must be small relative to the area of the population being studied for the sampling problem to make sense at all, this simplifying assumption is not restricting.

\section{EFFECT OF ALGORITHM EDGE ON SIMULATED SAMPLING}

In computer-simulated forest sampling, one starts with a matrix of tree coordinates and tree characteristics and selects random sample points within the boundaries of the forest. Wensel and John (1969) corrected for the fact that some randomly selected plots overlap the forest boundaries by computing the actual plot area to be used in the estimators (algorithm WGT).

Using data from the Cutfoot Experimental Forest (Wensel and John, 1969), figure 3 shows the variance functions for no-overlap correction, WGT correction discussed by Wensel and John (1969), and for the EDGE correction discussed above. These data resulted from the selection of 200 randomly located points within the bounds of the computer-represented Cutfoot forest and then constructing each of the three estimates at each point.

The uncorrected estimates resulted in a much higher variance than did corrected estimates (for all except the smallest plot sizes). The WGT-corrected estimates are plotted on nominal plot sizes and not on actual plot sizes-plotting on the actual plot size would move the WGT-corrected line to the left and make it even closer to the EDGE-corrected line shown in figure 3 . In terms 


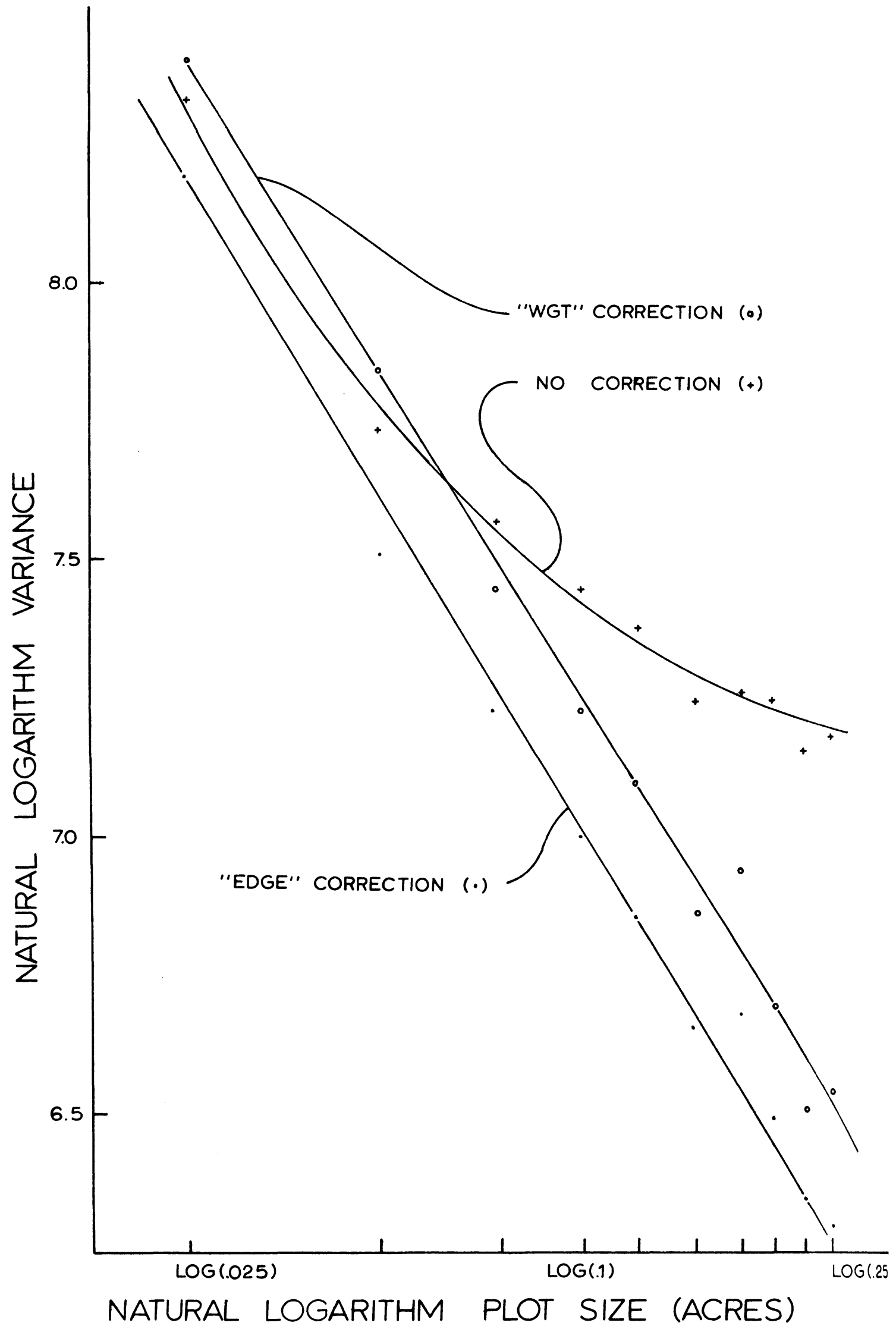

Fig. 3. Logarithm of variance of numbers of trees per acre on the logarithm of plot size. 
of statistical efficiency, the WGT and EDGE corrections are comparable.

In computer-simulated sampling studies, EDGE correction permits each tree within the population to be treated the same regardless of its proximity to the boundary.

\section{LITERATURE CITED}

BeERs, T. W.

1964. The direct correction for boundary-line slopover in horizontal point sampling. Purdue Ag. Expt. Sta. Research Progress Report 224.

\section{Grosenbaugh, L. R.}

1958. Point sampling and line sampling: probability theory, geometric implications, synthesis. So. For. Expt. Sta. Occ. Paper 160.

\section{KULOW, D. L.}

1966. Comparison of Forest Sampling Designs. Journal of Forestry 64(7):469-74.

O'Regan, W. G. and M. N. Palley

1965. A Computer Technique for the Study of Forest Sampling Methods. For. Sci. 11(1):99114.

WENSEL, LeE C.

1975. Computer Generation of Points on a Plane. Hilgardia 43(5):131-42.

WENSEL, L. C. and H. H. JOHN

1969. A Statistical Procedure for Combining Different Types of Sampling. For. Sci. 15(3): 307-17.

\section{APPENDIX}

\section{Computer Program ${ }^{1}$}

Routine

PROGRAM STAND

SUBROUTINE MODIFYP

SUBROUTINE LOCATE

FUNCTION F

FUNCTION G

SUBROUTINE PLOT

FUNCTION RANDOM

FUNCTION LSHIFT

\section{Function}

Main control of program

Modify probability matrix after each individual is located.

Locate the coordinates corresponding to the random number drawn.

Regular probability modification function Contagious probability modification function Plot the pattern generated on the line printer Generate uniform pseudo-random numbers Packs characters into computer words for MAP

${ }^{1}$ SUBROUTINE TSORTR, which sorts the indices of coordinates points modified by MODIFYP, is not listed. The user is advised to use whatever sort routine is available on his local computer. 
C

PROGRAM STAND(INPUT, DUTPUT,TAPEGEOUTPUT, PUNCH)

COMMON /DATA/ N,N:X,NY,NXY,W,A

COMMON /ID/ ID

COMMON /SCALFR/ $x_{0} Y$

DIMENSION P(6401), KOORD(200)

DIMENSION JP( $\triangle \cdot A O)$

EQUIVALENCF (P,JP)

INTEGER RR( 200$)$

DIMFNSION AMFAN(10) DAVAR(10) PRADIUS(10),PLOTS(10) PTREE(10). $X X(10), Y Y(10)$, NAMFILE $(B)$, $C(2.200), B O U N D(2,2)$

COMMON /RLOCK/GOUND,UNIT,SEED,N1,N2,N4,IZ,KP,NAMFILE

COMMON/MOIIIX,IY,OMAX, SUMPI , SUMP?.IK,ONN

COMMON /GRID/ GRID

COMMON /PAR/AA, RR, RK, B2, XO, XI, HM, R

COMMON /IP/ IP(25)

C

DOUELE PROR, SLIMPROR

READ 916 .NAMFILE

READ 917,M,N1,NZ,NA,IZ,KP,UNIT

READ 91B,NOTE, (RADIUS (I),III,M)

$C * * * * * M D D I F I C A T I O N$ FUR MULTIPLE SEEDS

READ 905. N, NX. NY. NXY. W. A

READ 910 . NITEK, SEEDI

IF (NOTE.EQ.3HSIZ) GO TO 15

DO $13 I=1, M$

13 PLOTS (I) $=(3,1415926536 * R A D I U S(I) * * 2) / U N I T$

Gก TO 18

15 DO $17 \quad I=1 . M$

PLOTS (I) =RADIUS (I)

17 RADIUS (I) =SART (UNIT*PLOTS (I)/3.1415926536)

18 CONTINUE

BOUND $(1,1)=0$.

BOUNA $(2,1)=0$.

BOUND $(1,2)=N X$

$B O U N D(2,5)=N Y$

DO 90 ITFR 1 I.NITER

PRINT 919, NAMFILE

READ 906 . ID. HM, X0. XI, HA, RA, BK, B?

SFEN = SEEDI

$N 2=1$

$N=(N X Y / W * 2) *(4.13 .14156)$

PRINT 50

PRINT 90?, N. NX, NY, NXY, W, A, ID

PUNCH 912, N,NX,NY,ID,W,A,HM,XO,XI,BA,BB,BK,BZ

PUNCH 1912

IF (ID) $6.7 \cdot 8$

6 PRINT 190?. XO, HM. BA, BB. BK

PRINT 907

PRINT ONB

GO TO 9

7 PRINT 913

GO TO 9 
B PRINT 290?, XI, XI, HN. HA. BH, RK, B?

PRINT 914

PRINT 915

C GENERATF INITIAL PROAARILITIES

9 PROR $=1$. $P$ INXY

$N X Y 1=N X Y+1$

SUMPROR $=-P R D B$

DO IO I $=1$. NXYI

SUMPROB = SUMMPHUR + PROR

$10 P(I)=$ SIIMPROA

DNN $=k$

GRID $=S O R T(A / N \times Y)$

C

DMAX IS THE MAXIMUM IISTANCE FROM TREE AT WHICH ANY POINT WILL BE MDIIFIFR.

DMAX $=$ ONN*XI

$R=D M A X / G R T D+0.5$

PRINT 9O4, GRIO, ONN, DMAX

CHECK ROUND OFF ERROR

I-TH TREF TO RE LOCATED HAS DIAMETER DIAM(I)

ISTART $=0$

PRINT 910.ISTART,SEFD

PRINT BOO

DO $30 \quad I=1, N$

$I I=I$

C SELECT RANDOM NIJMHER

RAND=RANDOM (SEED)

C LOCATE INIFX K SLCH THAT P(K-1) ILT. RAND ILE. P(K)

C

FATAI $=0$

$K=R A N D * N X Y$

CALL LOCATE (RAND, K, P, NXY1)

$k=k-1$

$I X=\operatorname{MOD}(K-1 \cdot N X)+1$

IY $=K \quad / N X+1$

$C(1, I)=I X$

$C(2, I)=I Y$

$K \cap O R D(I I)=I X * 8 * * 5+$ IY

25 PRINT 901 , I, RAND, $K$, RAND, IX, IY

IF $(T D, N E . O)$

ICALL MODIFY P (ID. K, P, ISTART, FATAL, NXYI.

NK)

IF ( FATAL,GT.0.) GO TO 90

30 CONTINUE.

PUNCH 916. NAMFILE

PUNCH $909,(K O O R D(I), I=1, N)$

CALL PLOT (KOORO.N $8.80,77777000009,777774.1,8 . J P, 15,0 . N A M F$ ILE)

CALL SPATIEL (AMFAN,AVAR,RR,C,RADIUS,PLOTS,TREE,XX,YY,M,N)

90 CONTINUIF

PRINT 903, FATAL

50 FORMAT (1H, //// 15X, *DATA* //, 10X, *SYMBOL*, 3X, *VALUE*, 7X,

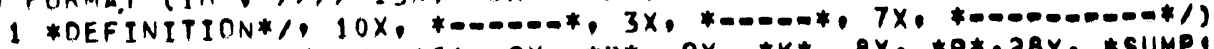

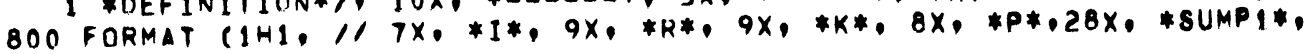

$15 x_{0}$ * SUMP $\left.2 * 1\right)$

901 FORMAT ( I8. F12.5, IB. 10X, n20. 2I10) 


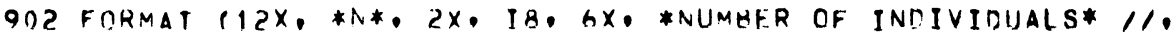

1 11x, *NX*,2X, IR, 6X, *NIJMBFR OF POINTS DN GRIN IN $X$ DIRFC

2TION* $1 / .11 x_{*} * Y *, 2 x$, I $Y, 6 x_{*} *$ NUMAFR OF POINTS ON GRID IN $Y$ DIRFC

3TION* $1 /, 90 X, * N X Y *, 2 X$. IB,6X**TOTAL NIIMRER DF POINTS ON GRID*/1,

$412 x_{0} * w *, 2 x_{0}$ FR.,$h x$. *AREA / (NO. OF TRFES)

5\%, $12 x, * A *$, F10,0, hX, *AKEA COUFRED PY POPUI ATION*

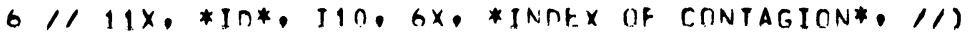
1902 FORMAT (
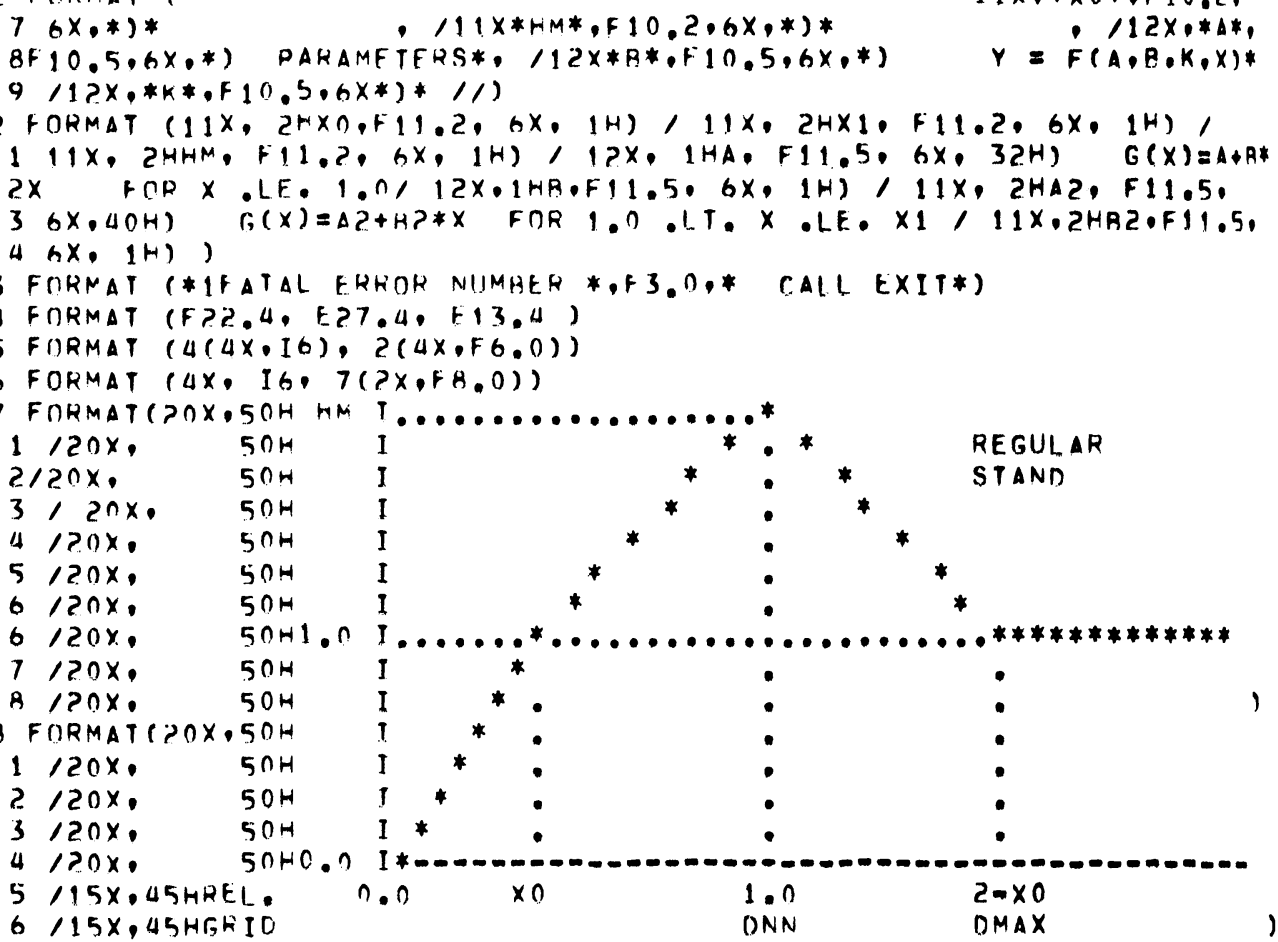

909 FORMAT $(8010)$

910 FORMAT (I3.2X.020)

912 FORMAT ( 4 I5. F5.0. F7.0. 3F5.?. $4 F B .4$ )

1912 FORMAT (7RH N NX NY ID W AREA HM XO XI A $913^{1}$ FORMAT (2OX.5OH HMT ${ }^{B}$ B? $)$ RANDOM STAND
$1 / 20 x_{0} \quad 50 \mathrm{H} \quad \mathrm{I}$
$2 / 20 x_{0} \quad 50 H 1.01 * * * * * * * * * * * * * * * * * * * * * * * * * * * * * * * * * * * * * * * * * * * *$
$3120 \times$. $50 \mathrm{H} \quad \mathrm{I}$
$4120 x_{0} \quad 50 H \quad I$
$5120 x_{0} . \quad 50 H \quad 1$
$6120 \times 0.50 \mathrm{H} I$

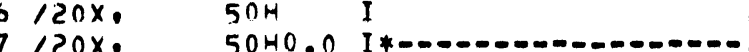
$8 / 15 x .45 H R F L$. 0.0
$9 / 15 X, 45 H G R I D$
1.0
DNN
CONTAGIOUS STAND

914 FORMAT $20 \times, 50 H$ HM I

$\begin{array}{lll}1 / 20 x_{0} & 50 \mathrm{H} & \text { I * } \\ 2120 X_{*} & 50 \mathrm{H} & \text { I } \\ 3120 X_{*} & 50 \mathrm{H} & \text { I }\end{array}$ 


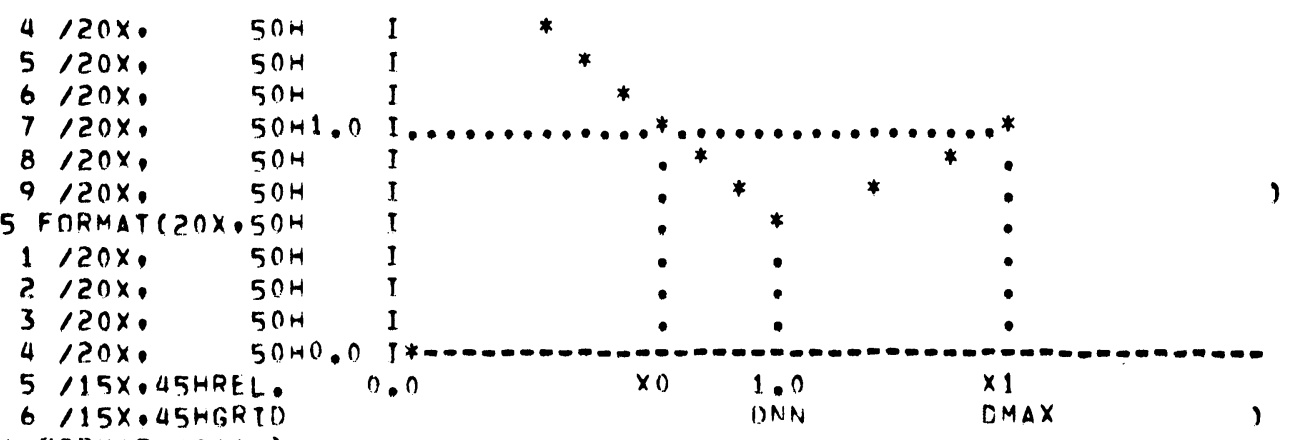

916 FORMAT (BA10)

917 FORMAT ( $4(15.5 X), A 5.5 X, I 5, F 10.2)$

918 FORMAT $(5 X, A 5,10 F 5.0)$

919 FORMAT (1H1,8A10)

END 
SURROUTINE MODIFY P (IN,KXY,P, ISTART, FATAL, NXYI,

EXISTING PRORARILITIES ARE MODIFTED BASED UPON

THE OUTCOME RF THF PREVIUUS TRFE LOCATION.

THE MAGNITUNE AND SIGN OF ID ARE USED TO SPECIFY THE KIND

OF MODIFICATION TO HE MADE. ID $=-3,-2,-1,0,1,2.3$

ID NEGATIVF = REGULAR DISTRIBUTIONS

ID TFRO = RANDOM DISTRIBUTION

IN POSITIVE = CONTAGIOUS OISTRIBUTIONS

ISTART $=0$ TO INITIALIZE CONSTANTS

DIMENSION P (NXY1), INDX (85O),Q(85O)

COMMON IDATA/ N,NXONY,NNN,W,A

COMMON/MOD/IX,IY,DMAX, SUMPI, SUMPZ,IK,DNN

COMMON /GRID/ GRID

COMMON /IP/ IP(25)

COMMON IPAR/HA, BP, BK, R2, $X_{0}, X_{1}, H M, R$

SUMP1 $=0$.

SUMPZ $=0$.

C NXY $=N X Y 1-1$

IF (ISTART.NE. O) GO TO 25

1. MODFL

REGUIAR DISTRIGUTION

(A) EQUATION $Y=K * X *(B-E X P(-A * X))$

(B) FOR $0, L E \cdot X \cdot L E, X 1, O, Y=F(X)=K * X *(B-E X P(-A * X))$

(C) FOR 1.0,LT,X,LT. $(2-X 0), Y=F(2-X)$

WHERE $x_{2}=\left(x_{0}=\left(x-x_{0}\right)\right),(1-x 0)$

(D) FOR $1.1 .1, X, L F,(2-\times 0), Y=F(1-\times 3)$

WHFRE $\times 3=(\times 0-((2-x)-\times 0) /(1-\times 0)$

CONTAGIOUS DISTRIBUTION

(A) EQUATION $X=D I S T A N C E$ FROM TREE

(FOR $X, E R . O) \quad Y=0$.

(FOR $0.1, T, X, I, E, 1) \quad Y=A+B X$

(FOR I.LT.X.LT.XI) $Y=A Z+B Z^{*} X$

II. VARIABLES, SCALF

DNN=DISTANCF TO NEAREST NFIGHROR ON HEXAGONAL SPACING, DNN=W/2,*SART (5.) WHERE $W=S Q R T(A / N)$.

DNN! IS THE SCALING PARAMFTER ON THE $X$ AXIS FOR THE MODELS IN SECTION I.

AEAREA COVERED BY POPULATION

$N=N U M B E R$ OF INDIVIDUALS IN POPULATION

GRID=PHYSICAL DISTANCE BETWEEN POINTS ON GRID (SQRT(A/NXY))

NXY=TOTAL. NUMEER OF POINTS ON GRIDENX*NY

PONNEPROBABILITY PEAK AT DNN, SCALING PARAMETER ON THE $Y$ AXIS FOR 


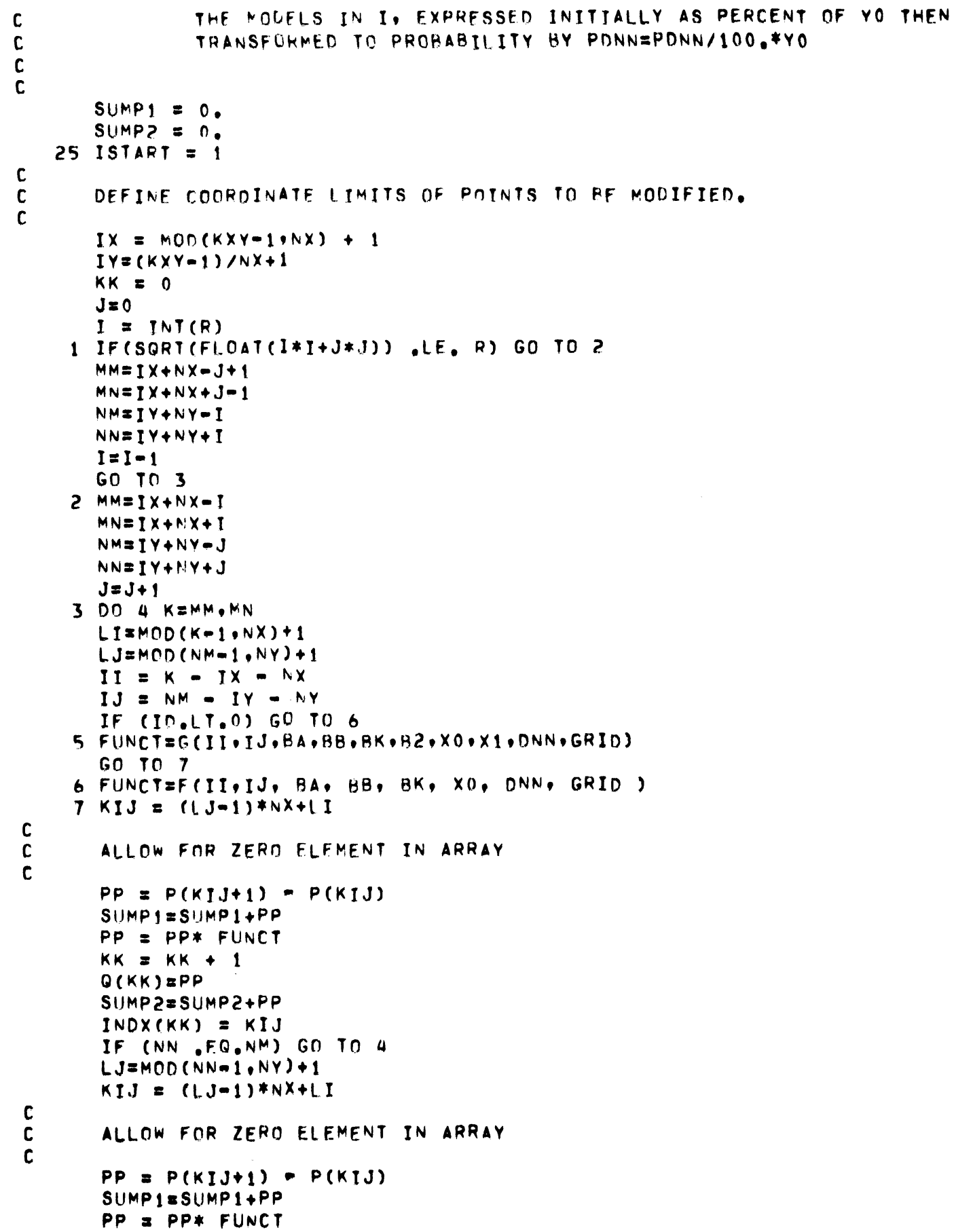




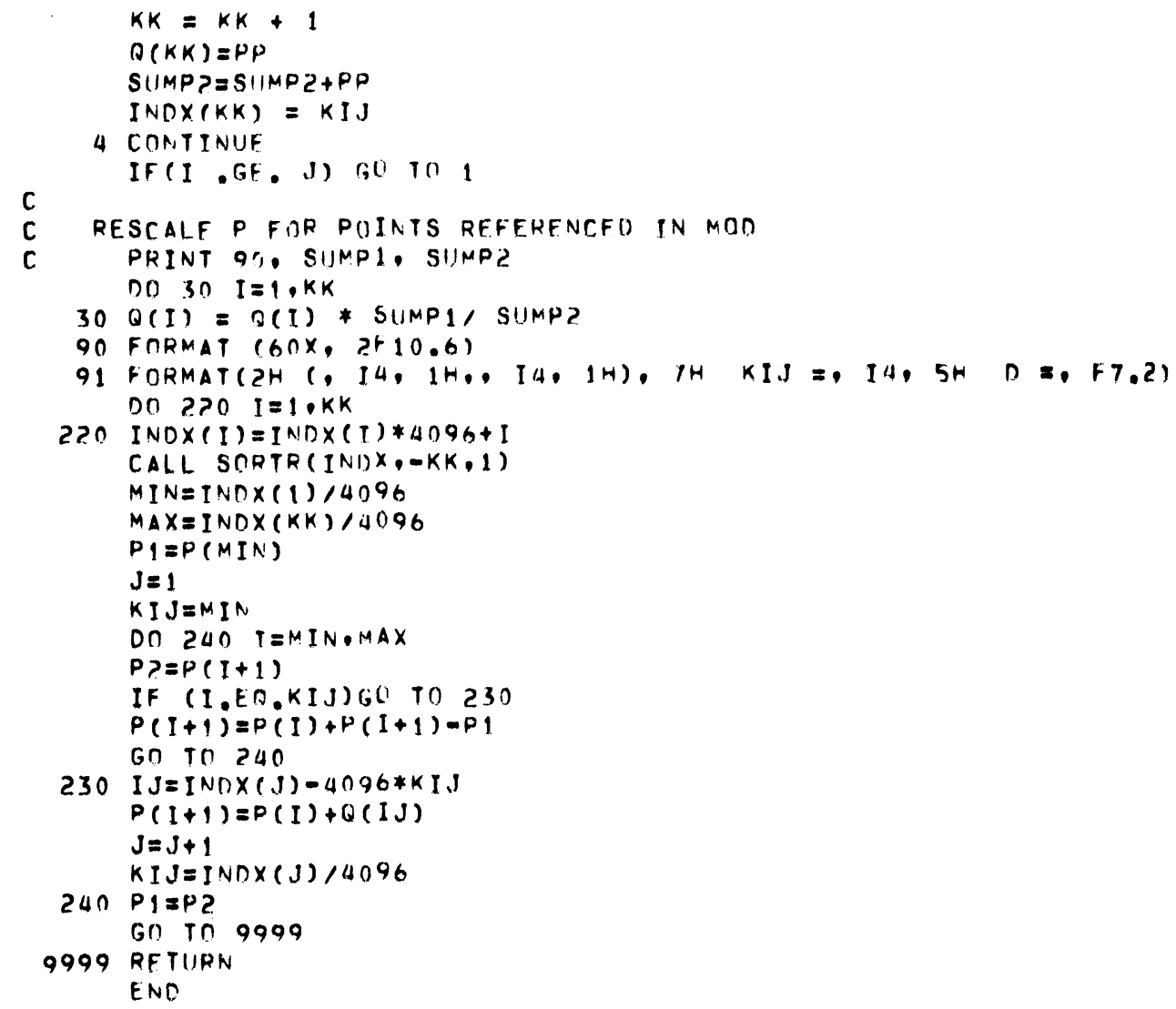




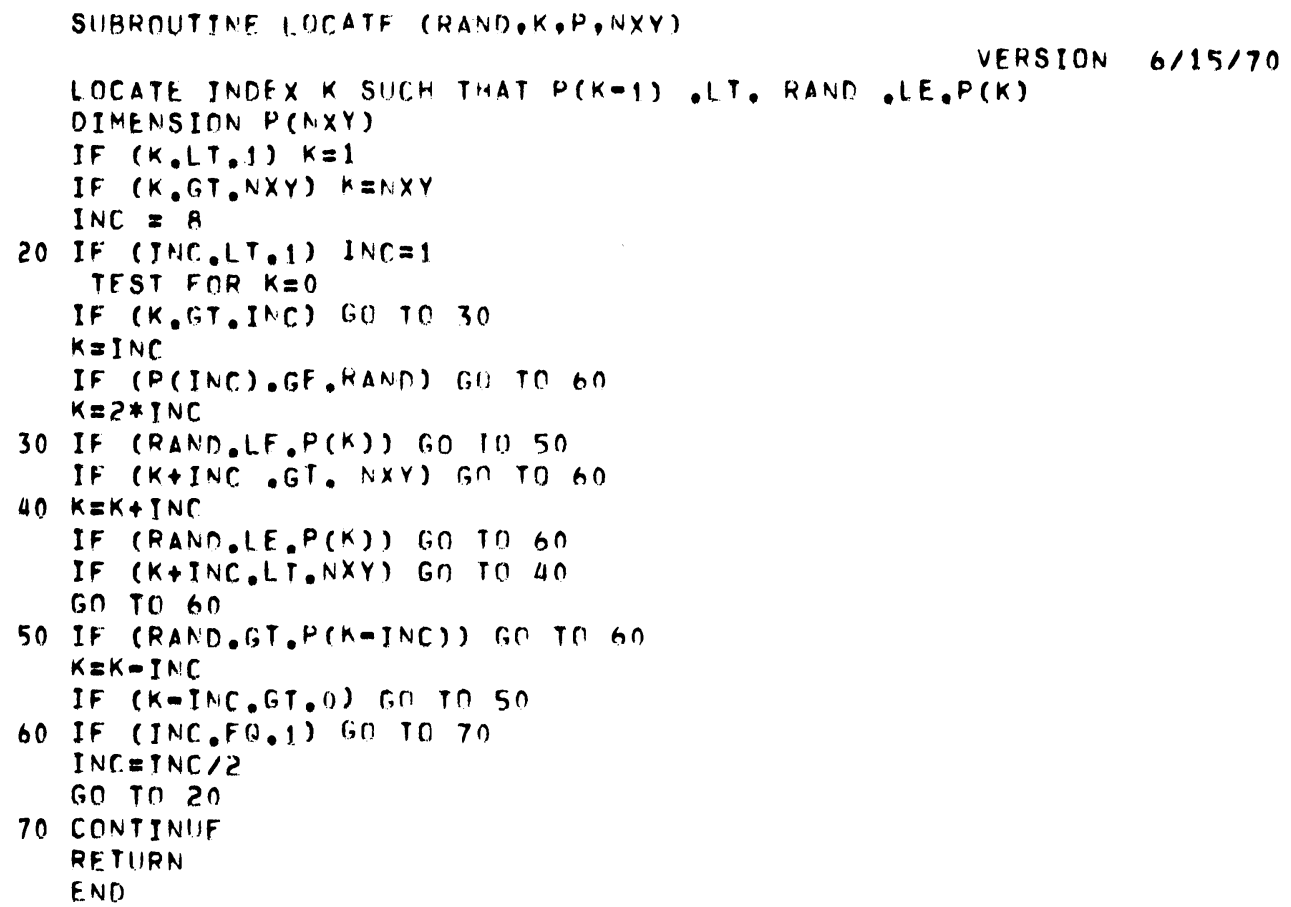




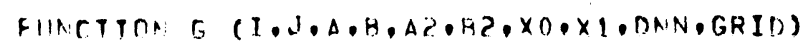

CONTALIRUS DISTRIBUTIOPN

MUNEL....G $=A+R * X$

CALCULATF PROHAHILITY MMOIFICATION $x=$ OISTARCE FROM ORIGIN

$\times n=$ DISTANIE WHERE RELATIVE PROBABILITY INCREASE CROSSES 1.0

C

C

$$
G=1 \text {. }
$$

$X=F I O A T(T) *$ KRIDIONA

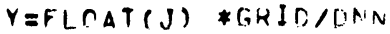

$x=\operatorname{SQRT}(X * x+y * Y)$

If $\left(x_{0}, G, X_{1}\right)$ GC TO 40

If $(x, G Y, 1$.$) GO TO 10$

$5 G=A+R * X$

If $\left(x, \& Q, O_{0}\right) G=0$.

40 RETURN

10 $G=A Z+A Z * X$

G) $\operatorname{t\rightarrow n} 5$

ENT 
FUNCTION F (J,J,A,F,K,XO,ONNGGRID)

DIMENSION C (3)

REAL $K$

$C$
$C$
$C$
$C$
$C$
$C$
$C$
$c$
$c$
$C$

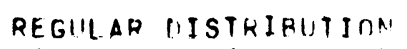


SUIBROUTINF PLOI (IZ,NHTS,MAXARS,MAXIRD.AHSMASK,OROMASK, ISCALE, ILINF. IP,IXPACK, IYPACK,RI (IRP)

SUBROIITTNE PLIIS POTNTS ON PRINTFR WITHMAXABS AND MAXORD BEING THE MAXIMUM NUMBER OF GRID POINTS IN THF HORITONTAL (X) AND VFRTICAL (Y) DIRFCTIONS.

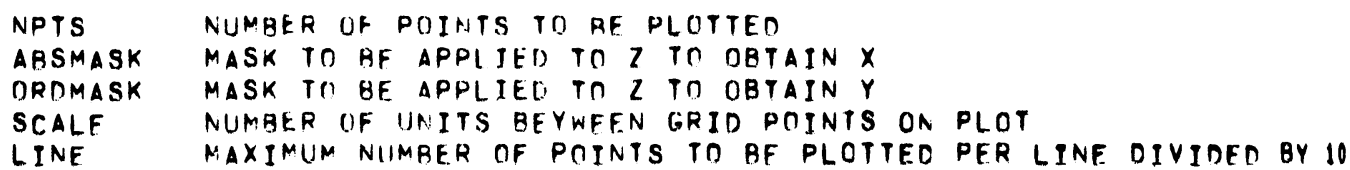

PRINT PRINTS

**** PAGE 1****

KNOELINIE

PRINT 90 P BLURP

PRINT $91,(I, I=1, K N O)$

PRINT 92

PRINT 93

DO $15 \mathrm{~J}=1, M \triangle X O R D$

$J J=M A X O R D-J+1$

$L 10=57 B$

$L 9=\quad J 3 / 100$

$L 8=\quad(J J-L 9 * 1 \cap 0) / 10$

$L 7=33 B+(J J-L 9 * 100-L B * 10)$

$\angle B=L 8+33 B$

$\angle 9=\angle Q+33 B$

IF $(L B, E Q, 33 B) \angle 8=55 B$

If ( $19 . E Q .338) \angle 9=55 B$

$L=(L 7+64 *(L B+64 *(L 9+64 * L 10)))$

$L=$ LSHIFT (L. -36$)$

15 PRINT $94, J J,(I P(I, J J), I=1, K N O), L$ PRINT93 
PRINT 92

PRINT $91,(I, I=1, \mathrm{KNO})$

PRINT 90

RFTURN

90 FORMAT (1H1/1X010A10)

91 FORMAT ( 5X.12110)

92 FDRMAT $\left(5 x_{0}, 8\left(9 x_{0} 1 H 0\right)\right)$

93 FORMAT ( $\triangle H Z$ - Bट(1H.))

94 FORMAT (1HZ.I3.1H..12AIO)

FND

FUNCTION RANDON (R)

$5 R=M O D(I F I X(R * 2147483647.0) * 455470314.2147483647) / 2147483647$. RANDOM $=R$

RETURN

END

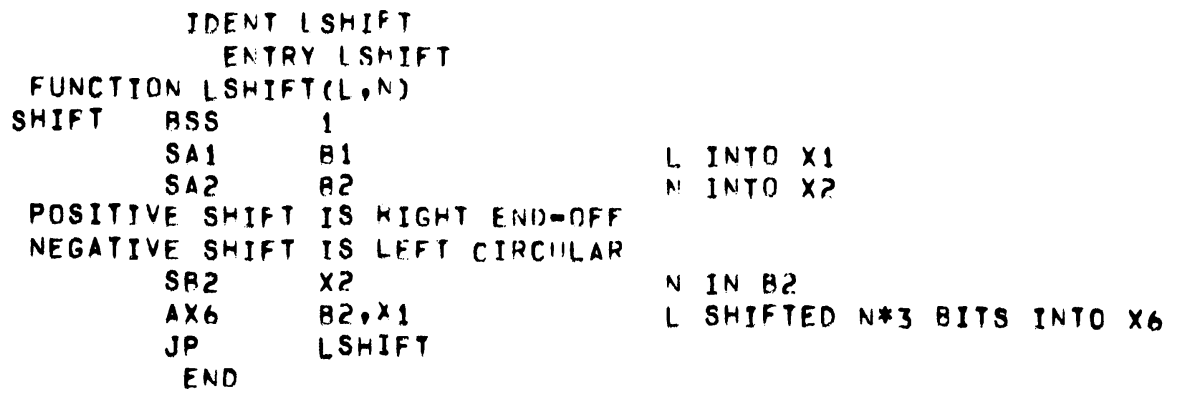

To simplify information, trade names of products have been used. No endorsement of named products is intended, nor is criticism implied of similar products which are not mentioned. 

The journal HILGARDIA is published at irregular intervals, in volumes of about 650 to 700 pages. The number of issues per volume varies.

Single copies of any issue may be obtained free, as long as the supply lasts; please request by volume and issue number from:

\author{
PUBLICATIONS \\ UNIVERSITY OF CALIFORNIA \\ DIVISION OF AGRICULTURAL SCIENCES
}

1422 South 10th Street

Richmond, California 94804 


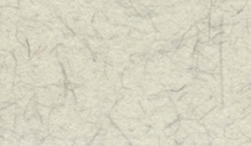

